\title{
Climatic control of seed longevity of Silene during the post-zygotic phase: do seeds from warm, dry climates possess higher maturity and desiccation tolerance than seeds from cold, wet climates?
}

Journal Article

Author(s):

Zani, Deborah; Müller, Jonas V.

Publication date:

2017-11

Permanent link:

https://doi.org/10.3929/ethz-b-000261176

Rights / license:

$\underline{\text { In Copyright - Non-Commercial Use Permitted }}$

Originally published in:

Ecological Research 32(6), https://doi.org/10.1007/s11284-017-1508-6 
Ecological Research, Received: 18 February 2017 / Accepted: 12 September 2017

The online version of this article (doi:10.1007/s11284-017-1508-6) is available to authorized users.

Climatic control of seed longevity of Silene during the post-zygotic phase. Do seeds from warm, dry climates possess higher maturity and desiccation tolerance than seeds from cold, wet climates?

\section{Deborah Zani ${ }^{\mathrm{A}, \mathrm{B}}$ and Jonas V. Müller ${ }^{\mathrm{A}}$}

${ }^{\text {A}}$ Millennium Seed Bank, Conservation Science, Royal Botanic Gardens Kew, Wakehurst Place, RH17 6TN, United Kingdom

${ }^{\mathrm{B} C}$ Corresponding author. Email: deborah.zani01@ gmail.com. Phone: (+39) 3403168849

Abstract. Seed longevity derived from artificial ageing experiments has been shown to be related to the macroclimate at the sampling site and with individual seed traits. Nevertheless, the ecological interpretation of artificial seed longevity remains to be clarified. In this article, the ecological significance of seed longevity expressed by the p $_{50}$ index was explored using 16 closely related populations of the genus Silene L. Seeds were subjected to an artificial ageing treatment at $45^{\circ} \mathrm{C}, 60 \%$ relative humidity $(\mathrm{RH})$ and regularly tested for germination. The decline of viability to $50 \%$ ( $\mathrm{p}_{50}$ index) was calculated using probit analysis. Its relationship with known ecological predictors of seed longevity was assessed by multiple regression analysis. Values of p50 ranged from 3.7 to 68.3 days. Seed lots which normally experience drought during the post-zygotic phase in a dry, warm environment, were long-lived. Consistently, precipitation during the driest months of the reproductive period was the strongest predictor of $\mathrm{p}_{50}$ variability (partial regression, $\mathrm{R}^{2}=0.424$ ). We could not find any relationship between $e x$ situ seed longevity and soil seed bank formation or seed size. Our results indicate that ex situ seed longevity has an ecological significance related to long-term climatic differences at population site. Increased longevity presumably reflects resistance to desiccation stress attained by seeds through local adaptation to warm, dry climates. We cannot exclude that seed tolerance to ageing could also represent phenotypic plasticity mediated by a drier maturation environment. The vulnerability of seeds from wet, cool climates and the adaptive response of seed longevity to different environments may have implications for ex situ conservation in the face of climate warming. 
Additional keywords: seed viability, climatic factors, desiccation stress.

\section{Introduction}

Seed longevity determines the storage potential of seed accessions held in ex situ collections such as germplasm banks and seed banks and, therefore plays a crucial role in securing the long-term survival of endangered species through ex situ conservation (Walters et al. 2005; Probert et al. 2009). Exposing seeds to a controlled ageing environment at $45^{\circ} \mathrm{C}, 60 \%$ relative humidity (RH) has been successfully employed to calculate an index of seed longevity expressed as the decline of viability to 50\% ( $\mathrm{p}_{50}$ index) for seeds preserved ex situ in seed banks (e.g. Ellis and Roberts 1980; Probert et al. 2009; Mondoni et al. 2011). Although the length of seed survival in ex situ collections declines predictably with increasing storage temperatures and higher seed moisture contents, seed longevity has been found to vary considerably among seed lots held in identical storage conditions (Walters et al. 2005). Such variation has been attributed to differences in taxonomy at family and/or genus level, macroclimate at the site of collection, or seed traits such as mass and oil content (Walters et al. 2005; Probert et al. 2009; Mondoni et al. 2011, 2014).

Although a measure of ex situ seed longevity obtained by controlled conditions in the laboratory may not explain the complex ageing response of seeds which occurs in nature, a number of studies have successfully used the $\mathrm{p}_{50}$ index to determine and interpret environmental-induced drivers of seed longevity (e.g. Probert et al. 2009; Mondoni et al. 2011, 2014; Bernareggi et al. 2015). We therefore assume that artificial ageing experiments in the laboratory can have an ecological significance. A screening of relevant literature reveals that ageing mechanisms tend to be ascribed to different and sometimes contrasting ecological causes. On one hand, Long et al. (2008) found evidence for a correlation between persistence in the soil under natural conditions and seed longevity estimated by laboratory experiments. Since individual seeds modulate their inclusion in the soil seed bank through germination and ageing (Kochanek et al. 2010), one can expect that seeds with higher resistance to ageing, thus long-lived in storage, would persist longer in the soil. On the other hand, in their extensive quantification of seed performance in storage, Walters et al. (2005) failed to detect a gene bank/soil seed bank correlation for seed longevity.

Following another hypothesis, ex situ seed longevity would reflect a selection pressure for seed resistance to ageing induced by local climatic factors, namely temperature and precipitation. A number of studies (e.g. Probert et al. 2009; Kochanek et al. 2010; Mondoni et al. 2011; Bernareggi et al. 2015) have stressed the importance of the climate of origin as the main driver 
of variation in seed longevity, with seeds from wet, cool environments tending to be shorterlived compared to those from warm, dry climates. Mondoni et al. (2014) observed that parental plants of Silene vulgaris growing in warmer environments might produce longer-lived seeds by promoting seed resistance to heat stress in the offspring. Furthermore, the fact that seeds experiencing drought during the period of maturation are characterized by longer life-spans (Kochanek et al. 2010) may suggest that desiccation tolerance determines a greater resistance to ageing in dry storage. The laboratory-derived index of seed longevity ( $\mathrm{p}_{50}$ index) might therefore reflect tolerance to heat and/or desiccation stresses exercised by the local environment.

In the presented study, to clarify the ecological significance of seed resistance to ageing in long-term storage as expressed by the $\mathrm{p}_{50}$ index, seed accessions from con-generic species of the genus Silene L. were subjected to artificial ageing and the estimated $\mathrm{p}_{50}$ values were analysed using known ecological predictors of seed longevity. Specifically, we tested the hypotheses that the $\mathrm{p}_{50}$ index is related to (i) seed mass; (ii) an index of seed bank formation based upon all interacting factors known to affect seed persistence in the soil, such as dormancy breaking cues and germination traits (i.e. delayed germination, light requirement and reaction to fluctuating temperatures; Saatkamp et al. 2011); and (iii) long-term climatic conditions at population site (i.e. 50 years averages of temperature and precipitation).

\section{Materials and Methods}

\section{Seed material}

Seeds were selected from collections held for long-term conservation storage at the Millennium Seed Bank (Royal Botanic Gardens Kew, United Kingdom), according to seed availability, high initial viability (>80\%) and to provide a broad climatic coverage (Fig. 1). Collections represent 11 species of the genus Silene L. (Caryophyllaceae), with four species including 2-3 populations from localities across Europe, the Near East and North America. Seeds were collected at the point of natural dispersal from fully ripened fruits between May and September and stored under international gene bank standard conditions $\left(15 \% \mathrm{RH}\right.$ and $-15^{\circ} \mathrm{C}$; FAO/IPGRI 1994) at the Millennium Seed Bank for between 1 and 4 years (Table S1). Correlation analysis was performed to determine whether $\mathrm{p}_{50}$ is related to the time spent in storage prior to the commencement of the ageing experiment (B-E) or to the period between harvesting and banking (H-B). The relationship turned out to be statistically non-significant $\left(\mathrm{R}^{2}=0.151\right.$ and $\mathrm{R}^{2}=0.004$, respectively; Table $\mathrm{S} 1$ ), indicating that the time spent between harvesting and the start of the experiment was unlikely to affect ex situ seed longevity of the studied species. For 
each accession, mean seed mass was calculated by weighting five lots of 50 seeds (equilibrated to $15 \% \mathrm{RH}, 15^{\circ} \mathrm{C}$ ). For more detail on seed material see Table 1 and Table S1.

\section{Artificial ageing and germination tests}

Artificial ageing experiments were conducted between March and June 2016 at the Millennium Seed Bank, using a standard protocol (Davies and Probert 2004). For all accessions, eight samples of 90 seeds each were pre-equilibrated at $47 \% \mathrm{RH}$ and $20^{\circ} \mathrm{C}$ for 2 weeks and then moved to the ageing environment of $60 \% \mathrm{RH}$ at $45^{\circ} \mathrm{C}$. The atmosphere of both environments was maintained within sealed 300 × 300 x 130 mm electrical enclosure boxes (Ensto UK Ltd, Southampton) by a non-saturated solution of $\mathrm{LiCl}$. The $\mathrm{RH}$ value was checked every 2 weeks and re-equilibrated, if necessary (Hay et al. 2008). Samples were removed from the ageing environment after 0, 5, 10, 15, 20, 30, 50 and 70 days for germination tests. Seeds from each sample were uniformly sown on $1 \%$ agar in distilled water in three replicates of 30 seeds (Baskin and Baskin 1998) and placed in temperature $\left( \pm 1^{\circ} \mathrm{C}\right)$ and light (ca. $\left.40 \mu \mathrm{mol} \mathrm{m} \mathrm{m}^{-2} \mathrm{~s}^{-1}\right)$ controlled incubators at conditions (range and temperature regimes) previously found to be optimal for each accession (Table 1). Germination events were recorded weekly, with germination being defined as visible radicle protrusion of $3 \mathrm{~mm}$ (Ellis et al. 1985). At the conclusion of the experiment, germination percentages were corrected for viable seeds through cut-tests; empty seeds were excluded from the test.

\section{Index of soil seed bank formation (SBI)}

An index of soil seed bank formation (SBI) was based upon all interacting factors known to affect seed persistence in the soil, which include dormancy breaking cues and germination traits. The process of dormancy breaking in a winter soil seed bank can be simulated artificially by cold stratification (Godefroid et al. 2011). Seeds of all accessions were therefore coldstratified at $-5 / 5^{\circ} \mathrm{C}$ for 2 weeks. Cold stratification was tested under variables previously found to overcome dormancy with optimal results; i.e. fluctuating temperatures at a sufficient low mean temperature (ca. $0{ }^{\circ} \mathrm{C}$, as the $5{ }^{\circ} \mathrm{C}$ range might cause precocious germination during the period of chilling). The duration of the test was determined using the ENSCONET Germination Database Report (http://ensconet.maich.gr/Database.htm), which indicates that for most tested accessions a two-week period under pre-treatment conditions was sufficient (Zani and Müller, unpublished data). The relative index of cold stratification requirement $\Delta G_{\mathrm{CS}}$ was calculated as follows: 
where $G_{\mathrm{CS}}$ and $G_{\mathrm{opt}}$ are the number of germinated seeds at optimal temperature with and without applying cold stratification, respectively. An increase in germination rate induced by the pre-chilling treatment is signalled by positive values of $\Delta G_{\mathrm{CS}}$ and likely indicates a winter dormancy syndrome (Mondoni et al. 2009).

Saatkamp et al. (2011) have shown that soil seed persistence can be related to delayed germination as quantified by $\mathrm{T}_{50}$ (days required to reach $50 \%$ of germination), light requirement (PGI, index of light requirement for germination; Koutsovoulou et al. 2014), and reaction to alternating temperatures $\left(\Delta G_{\mathrm{FT}}\right.$, index of fluctuating temperatures requirement) (Table 2):

$\mathrm{T}_{50}=\mathrm{t}_{\mathrm{i}}+\left[\left(\mathrm{N} / 2-\mathrm{n}_{\mathrm{i}}\right) *\left(\mathrm{t}_{\mathrm{i}}-\mathrm{t}_{\mathrm{j}}\right)\right] /\left(\mathrm{n}_{\mathrm{i}}-\mathrm{nj}\right)$

in which $\mathrm{N}$ is the final number of emergence and $\mathrm{n}_{\mathrm{i}}$ and $\mathrm{n}_{\mathrm{j}}$ indicate the cumulative number of seeds germinated by adjacent counts at the $\mathrm{i}^{\text {th }}$ and $\mathrm{j}^{\text {th }}$ time, respectively, when $\mathrm{n}_{\mathrm{i}}<\mathrm{N} / 2<\mathrm{n}_{\mathrm{j}}$;

$\mathrm{PGI}=1-(\mathrm{FGD} / \mathrm{FGL})$

where FGD and FGL are the percentages of germination in the dark and the light, respectively. The PGI results in values between 0 and 1 with a value of 0 corresponding to the germination percentage as equal in both light and darkness, while a value of 1 corresponds to germination only occurring in the light;

$\Delta G_{\mathrm{FT}}=\left[\left(G_{\text {fluct }}-G_{\text {const }}\right) /\left(G_{\text {fluct }}+G_{\text {const }}\right)\right] * 100$

where $G_{\text {fluct }}$ and $G_{\text {const }}$ are the number of seeds germinating at fluctuating and constant temperatures, respectively. Therefore, $\Delta G_{\mathrm{FT}}<0$ indicates that seeds germinate better under constant regime whereas $\Delta G_{\mathrm{FT}}>0$ occurs when fluctuating temperatures promote germination. In order to reduce SB traits $\left(\Delta G_{\mathrm{CS}}, \mathrm{T}_{50}, \mathrm{PGI}\right.$, and $\left.\Delta G_{\mathrm{FT}}\right)$ to one meaningful index, principal component analysis (PCA) was performed on the z-transformed SB traits and the most explicative component (PC1) retained as index of seed bank formation (SBI). Correlations of single SB traits to PC1 were assessed by non-parametric Spearman rank correlation coefficients. Lastly, Walck et al. (2005) have stressed the importance of placing seed bank 
formation in a plant life-cycle context, especially in the case of species with pronounced seasonal patterns as is the case with the present study. Thus, the germination pattern of each accession was used to locate the beginning and the end of soil bank formation at the seed dispersal peak and the germination event, respectively, in order to confirm the validity of SBI (Table 2).

\section{Climatic data}

Prevailing climatic conditions at the original sampling sites (temperature and precipitation) were extracted from WORLDCLIM dataset (download version 1.3 http://www.worldclim.org/; Hijmans et al. 2005) at a resolution of 2.5 minutes, based on data collected between 1950 and 2000. The period of plant activity was divided into three life cycle phases: (i) pre-zygotic, from the seedling to the flowering time; (ii) post-zygotic, including seed maturation up to dispersal; and (iii) post-dispersal, which may describe immediate germination (i.e. period of seedling establishment) or a quiescent period with no vegetative activity (i.e. overwintering). We derived the period of flowering for the studied species from Flora Europaea (Tutin 1980), Flora Iberica (Castroviejo et al. 1990), Flora of North America (Flora of North America Editorial Committee 1993) and the Red Data Book of the Republic of Bulgaria (Bulgarian Academy of Sciences 2011), whereas the time of seed dispersal was recorded on the field for each accession at the time of collection (Table 2). The time of germination and seedling establishment was estimated by Zani and Müller (unpublished data). According to the germination strategy adopted, the period of each phase varied with different populations (Table S1). Averages of temperature and precipitation were subsequently calculated for each accession by annual (= mean of all weekly mean values) and seasonal trends (= mean values for spring, summer, autumn and winter months, with seasons following the traditional solar timing of Europe and East Asia), and for each life cycle phase (Table 3). Next, in order to reduce the number of climatic explanatory factors and ensure their independence, principal component analyses (PCA) was performed on the z-transformed climatic variables and principal components (PCs) retained as climatic traits. PCA-axis scores were tested for correlation with single climatic variables by Spearman rank correlation coefficients (Table 4).

To assess whether long-term drought during the seed maturation period affected ex situ seed longevity, the heat-moisture index of the post-zygotic phase (PHM) was calculated for each seed origin (modified by Wang et al. 2006). The index PHM is given as $\left(\mathrm{P}_{\text {temp }}+10\right) /\left(\mathrm{P}_{\mathrm{pr}} / 100\right)$, where $\mathrm{P}_{\text {temp }}$ and $\mathrm{P}_{\mathrm{pr}}$ are the 50 years averages of temperature $\left({ }^{\circ} \mathrm{C}\right)$ and precipitation $(\mathrm{mm})$, respectively, using the post-zygotic months as time-scale. Drought was registered within the 
seed maturation period with $\mathrm{PHM}>50$ (moderate drought: $50<\mathrm{PHM}<100$; severe drought: $100<$ PHM <200; extreme drought: PHM>200) (Table 3). Although actual weather data from the seed ripening period were not available for each seed accession at the specific sampling location, WORLDCLIM data allow the assessment of long-term climatic differences among population sites, as is the goal of the present study.

\section{Statistical analysis}

A generalized linear model (GLM) with binomial error and probit link function was carried out on the data from the experiments (numbers of seeds germinating, numbers of seeds sown) using GenStat Release 11.1 to calculate the time for viability to fall to $50 \%$ ( $\mathrm{p}_{50}$ index),

$$
v=K_{\mathrm{i}}-(p / \sigma)
$$

where $v$ is the viability (in normal equivalent deviates, NED) of the seed accession after $p$ days in storage; $K_{\mathrm{i}}$ is the initial viability (NED) and $\sigma$ is the time (days) for viability to fall by 1 NED (Ellis and Roberts 1980).

Relationship between seed longevity $\left(\mathrm{p}_{50}\right)$ and all potential explanatory factors (seed mass, index of drought of the post-zygotic phase PHM, index of seed bank formation SBI, and climatic traits as expressed by PCA-axis scores) was assessed by multiple regression analysis using backward elimination in Minitab version 13. The initial model was computed with all predictors included (full model); at each subsequent step the least significant variable was eliminated and the model re-fitted until all remaining variables were significant $(p<0.05$; reduced model) (Probert et al. 2009).

\section{Results}

For all seed lots, seed viability declined as the period of artificial ageing increased, with the exception of S. caliacrae (Fig. 2) which was identified as an outlier during multiple regression analyses (Cook's distance>1) and subsequently excluded from the dataset. Across the remaining accessions, we found a wide variation in seed viability ranging from $3.7 \mathrm{~d}$ for $S$. nutans (ID9) to $68.3 \mathrm{~d}$ for S. reuteriana (ID14) (Table 1). When comparing the time taken for viability to fall to $50 \%$ within different populations of the same species, only accessions belonging to $S$. nutans (ID9-10) and S. otites (ID11-13) showed intraspecific variability. The alpine population of S. nutans (3.7d; ID9) was shorter-lived than the population of Continental provenance (21.5d; ID10) and nearly six times less resistant to ageing, whereas the 
Mediterranean accession of $S$. otites (ID12) was the longest-lived within the species (45.1d vs. 32.9d and 27.4d for ID11 and ID13, respectively; Table 1).

The principal component analysis (PCA) on soil seed bank (SB) traits extracted one factor $(\mathrm{PC} 1=70.32 \%)$ which exhibited high and significant correlations with all SB traits and was therefore retained as index of soil seed bank formation (SBI) (Table 4). The ecological meaning of SBI was confirmed by the estimated periods of seed dispersal and germination for each accession, with $\mathrm{SBI}>0$ indicating the formation of soil banks during winter or flooding seasons, and the absence of soil seed banks signalled by $\mathrm{SBI}<0$ (Table 2). The PCA performed on climatic variables explained $82.9 \%$ of the variance (Table 4) and extracted three principal components. The first factor $(\mathrm{PC} 1=45.1 \%)$ was positively correlated with all temperature variables at all time scales, thus representing the only trait for "temperatures", whereas precipitation variables were described by the second $(\mathrm{PC} 2=22.6 \%)$ and third $(\mathrm{PC} 3=15.1 \%)$ factors. In particular, precipitation variables of the plant activity phases and summer correlated with PC2, describing "precipitation during the driest months of the reproductive period", while PC3 explained the remaining precipitation variables ("annual and seasonal precipitation") (Table 4).

The regression model constructed using all explanatory variables (seed mass, index of drought of the post-zygotic phase PHM, index of seed bank formation SBI, and climatic traits as expressed by PCA-axis scores) accounted for $84.6 \%$ of the variation in seed longevity $\left(\mathrm{R}^{2}=0.846, \mathrm{~F}=13.782, \mathrm{p}<0.001\right)$. Backward elimination excluded seed mass and $\mathrm{SBI}$ as predictors of $\mathrm{p}_{50}$ and generated a reduced model $\left(\mathrm{R}^{2}=0.863, \mathrm{~F}=23.998, \mathrm{p}<0.001\right)$ which included all climatic traits (PC1, PC2, PC3) and the index of drought (PHM). In the reduced model, partial regression analysis indicated a positive relationship between $\mathrm{p}_{50}$ and the explanatory variable for temperature as expressed by PC1, accounting for $27.5 \%$ of the variance (Fig. 3a). Negative and stronger relationships between $\mathrm{p}_{50}$ and the explanatory variables for precipitation were also observed. Annual and seasonal trends of precipitation explained $29.6 \%$ of the variation (partial regression, $\mathrm{R}^{2}=0.296$; PC3; Fig. 3b), while a better fit was detected if only the mean rainfall level of the driest months during the reproductive period (PC2) was considered as predictor (partial regression, $\mathrm{R}^{2}=0.424$; PC2; Fig. 3c). Seeds from drier and warmer environments tended therefore to survive for longer times in dry storage. This is consistent with the positive and strong relationship observed between $\mathrm{p}_{50}$ and the index of drought of the post-zygotic phase (PHM), which accounted for a high proportion of the variance in the reduced model (partial regression, $\mathrm{R}^{2}=0.412$; PC1; Fig. $3 \mathrm{~d}$ ). 
274 Though the long-term survival of seeds in seed bank storage seems to be shaped by the local environment, the degree to which this trait can be ecologically determined is constrained by the species genetic background at the family and/or genus level (Walters et al. 2005). By selecting closely related populations of the same genus, we tried to control phylogenetic effects at the interspecific level and to evaluate the contribution of intraspecific variability. This approach of relating seed traits to the local environment at the species level was likewise adopted by Carta et al. (2016) to test whether germination preferences in Romulea seeds of phylogenetically related species reflected environmental conditions through local adaptation or phylogenetical constraints. The detection of meaningful differences in germination strategies associated with the local environment led the authors to argue for evolutionary adaptation mediated by phylogenetic relatedness. In the present study, intraspecific variation was found only among populations of widely differing climates for seed lots of S. nutans and S. otites, namely wet-cold (nearly three-fold in the alpine accession of $S$. nutans, ID9 vs. ID10) and dry-hot (nearly two-fold in the Mediterranean accession of S. otites, ID12 vs. ID13). Differences in seed longevity among sampled populations of S. flos-cuculi and S. latifolia alba, which occurred in relatively uniform habitats (i.e. marshland and temperate semi-dry grassland, respectively; Zani and Müller, unpublished data), failed to emerge. In agreement with Carta et al. (2006), we can hypothesize that variation of seed longevity under storage conditions reflects differential responses to the local climate attained by seeds through long-term adaptation rather than phylogenetic changes among our seed lots. However, the effect of the parental growth environment on seed ageing cannot be ruled out (Mondoni et al. 2014). Although we interpreted our results in terms of long-term climatic differences based on 50 years averages, WORLDCLIM predictions have been shown to strongly correlate with actual weather conditions during the seed ripening period (Fernández-Pascual et al. 2015). Therefore, we cannot exclude that climatically-related variation of longevity in our seed lots represents phenotypic plasticity mediated by the actual seed maturation environment. In this case, further investigations considering common garden experiments or reciprocal transplanting are required to disentangle plasticity from genetic effects.

In contrast to findings by Long et al. (2008), this study did not validate the hypothesis that seed life-span calculated by laboratory experiments is a reflection of seed persistence under natural conditions. In this regard, the case of alpine species is revealing. Seeds of alpine plants have been observed to be short-lived in storage (Mondoni et al. 2011), whereas they have a propensity to form long-term persistent soil seed banks in their natural environment 
(Schwienbacher et al. 2010). The fact that seeds from cool, wet climates (i.e. alpine) have low resistance to laboratory-induced ageing at high temperature and partial hydration $\left(45^{\circ} \mathrm{C}, 60 \%\right.$ $\mathrm{RH})$ despite showing high persistence in the natural environment may suggest that alpine climates do not exert on seeds much selection pressure for resistance to ageing since seeds under cool and fully hydrated conditions deteriorate slowly (Mondoni et al. 2014). Results of accelerated ageing experiments would thereby reflect climatic conditions at the population site rather than persistence in the soil seed bank. Accordingly, no significant relationship between the propensity to form soil banks and seed longevity in dry storage was revealed in our study, as the index of soil seed bank formation (SBI) was dropped during backward elimination along with 'seed mass' (Table 5). In agreement with our results, Probert et al. (2009) did not retain seed mass as a robust variable in the equation to predict seed life-span under storage conditions. Contrary to other authors (Thompson et al. 1993; Bekker et al. 1998; Arroyo et al. 2006) which found seed size to be related to soil longevity, no significant correlation between 'seed mass' and SBI was detected in our study (Table 5). Similarly, Saatkamp et al. (2011) excluded seed size as a predictor for persistence in the soil.

Climatic conditions experienced by the plants at the site of collection are likely be the main driver of viability for seeds in ex situ storage. The relationships observed between seed longevity and explanatory climatic factors support the notion of warm, dry climates originating long-lived seeds (e.g. Probert et al. 2009; Kochanek et al. 2010). For example, high temperatures and low levels of precipitation that characterize the Anatolian bioregion (with up to three months of water shortage in summer) were associated with the highest value for seed longevity (S. reuteriana, ID14; $\mathrm{p}_{50}=68.3 \mathrm{~d}$ ). At the other end of the spectrum, seeds of the alpine S. nutans (ID9; $\mathrm{p}_{50}=3.7 \mathrm{~d}$ ), which grows under the wettest and coolest environmental conditions analysed in our study, presents the lowest $\mathrm{p}_{50}$ value. Our results are consistent with Mondoni et al. (2011) who found that seed lots growing in alpine regions were considerably shorterlived than lowland populations of the same taxa.

In their extensive study of the ecological predictors of ex situ longevity for seed bank-collected seeds, Probert et al. (2009) hypothesized that enhanced longevity evolved as an adaptation to hot, dry environments where seeds are required to survive under drought regime before successful seedling establishment. Kochanek et al. (2010) observed that dry conditions associated with warm temperatures during the seed development and ripening phase led to an increase in the viability of Wahlenbergia tumidifructa seeds. Similarly, Sinniah et al. (1998) found that the life-span of Brassica campestris seeds was enhanced if plants underwent a period of water shortage during seed development. This is consistent with our results that precipitation 
during the period of plant activity was more critical than mean annual precipitation or precipitation outside of the life cycle phases (Table 5). Furthermore, the positive relationship of seed longevity with both, drought experienced during the post-zygotic phase (Fig. 3d) and temperature at population site (Fig. 3a) suggests that seed resistance to ageing can be related to the level of maturity normally attained by seeds in the local environment. Exposure to elevated temperatures combined with dry conditions during the post-zygotic phase promote seed ripening to full maturity which, in turn, determines higher initial viability and/or lower rates of germinability decline (Hay and Smith 2003; Probert et al. 2007; Bernareggi et al. 2015). Thus, seeds from hot, dry climates can attain a higher degree of maturity and potentially increase their longevity in storage. On the other hand, cooler climates with short growing seasons (i.e. alpine region) are characterized by a contracted phase of seed development that negatively affects seed ripening and thus longevity (Mondoni et al. 2011; Bernareggi et al. 2015).

Apart from enhancing the quality of seeds in term of initial viability, a higher degree of maturity can increase long-term survival in dry storage by promoting seed resistance to desiccation stress. The last phase of seed development on the maternal plant coincides approximatively with the acquisition of desiccation tolerance (Ellis et al. 1987; Welbaum and Bradford 1989), especially if seed maturity is attained under conditions of water-shortage which impose a further selective pressure for resisting dry conditions (e.g. Kochanek et al. 2010). This would explain why seed lots of Silene which normally experience drought during the maturation phase were longer-lived (Fig. 3d). Desiccation-tolerant seeds are better equipped to withstand the oxidative damage caused by abrupt changes in seed moisture content that inevitably take place during seed bank processing and accelerated ageing treatment (Donà et al. 2013). By hampering the activity of anti-oxidant molecules (inducing the formation of reactive oxygen species and subsequent DNA damage), dehydration and imbibition tend to impair the longevity of seeds lacking tolerance to desiccation stress (Rajjou and Debeaujon 2008; Waterworth et al. 2010; Ventura et al. 2012; Donà et al. 2013).

Optimal conditions for the increase in ex situ longevity (i.e. peak maturity and desiccation tolerance) are likely met when the post-zygotic phase of seeds is confined to the warmest and driest period of the year. The fact that our most critical precipitation variable retained 'summer precipitation' along with variable of the period of plant activity, thus describing rainfall during the driest months of the reproductive period (PC2, Table 5), suggests that our hypothesis is consistent. In a previous study (Zani and Müller, unpublished data), the germination strategy of seed lots from arid biogeographical regions (Anatolian, Macaronesian and Mediterranean 
regions) were characterized by an autumnal emergence pattern with the maturation phase during the summer months (Table S1). Consistently, the highest $\mathrm{p}_{50}$ values in the current study are associated with seed lots from arid bioregions. On the other hand, seeds from wet, cool environments which have normally contracted growing seasons suffer from greater desiccation sensitivity due to a reduced period of maturation on the maternal plant located outside summer months, thereby resulting short-lived in storage (e.g. Daws et al. 2004).

Finally, S. caliacrae (ID1) was identified as an outlier and excluded from the multi-regression analysis. Apart from a $\mathrm{p}_{50}$ value (ID1; $\mathrm{p}_{50}=203.8 \mathrm{~d}$ ) almost three times higher than the highest value retained in the analysis (ID14; $\mathrm{p}_{50}=68.3 \mathrm{~d}$ ), the survival curve of $S$. caliacrae (Fig. 2) presents an anomalous increase of seed germinability from 0 (74\%) to 10-30 (ca. 96\%) days of ageing treatment, whereas seed viability should normally decline with increasing time of storage (Ellis and Roberts 1980). Zani and Müller (unpublished data) found that this species requires elevated temperatures $\left(>25^{\circ} \mathrm{C}\right)$ to germinate optimally and that climatic conditions at the site of collection determined the optimal range of temperature. It is possible that warm ageing conditions $\left(45^{\circ} \mathrm{C}\right)$ acted as an environmental cue for germination and after-ripened of S. caliacrae seeds, with nearly $100 \%$ of germinability during the first weeks. After 30 days of treatment, the seeds suffered the inevitable viability decline that takes place during artificial ageing (Ellis and Roberts 1980; Probert et al. 2009). Subjecting S. caliacrae seeds to a period of warm stratification prior to the commencement of the ageing experiment may help in fixing their irregular response to the treatment.

In this study, we clarified the ecological significance of ex situ seed longevity due to its important implications for the effective management of seed collections held in seed banks. We showed that climatic conditions likely affect ex situ longevity by selecting seed tolerance to desiccation stress through local adaptation to long-term conditions or phenotypic plasticity mediated by the seed maturation environment. The increased desiccation tolerance of seeds from warm, dry climates (reflected in a greater resistance to ageing conditions) might result from a higher degree of seed maturity attained under climatic conditions (high temperatures associated with drought regime) normally experienced during the post-zygotic phase in the local environment. The vulnerability of desiccation-sensitive seeds produced in wet, cool climates (i.e. alpine, Arctic and Boreal regions), which are predicted to be specifically targeted by climate warming, should be considered when selecting accessions for long-term conservation in germplasm banks (Mondoni et al. 2011, 2014; Bernareggi et al. 2015). In this light, transgenerational artificial ageing experiments might empirically test the plastic effect 
exerted by climate warming on ex situ longevity of seeds from differing climates, exposed or not to seasonal drought.

\section{Acknowledgments}

We thank the Royal Botanic Gardens, Kew for the seed material provided. We would like to thank Dr Angelino Carta and Dr Eduardo Fernández-Pascual for providing useful comments on the manuscript. To the best of our knowledge, no conflict of interest, financial or other, exist.

Conflict of Interest: The authors declare that they have no conflict of interest.

\section{References}

Arroyo MTK, Chacón P, Cavieres, LA (2006) Relationship between seed bank expression, adult longevity and aridity in species of Chaetanthera (Asteraceae) in central Chile. Ann Bot 98:591-600

Baskin CC, Baskin JM (1998) Seeds: Ecology, Biogeography, and, Evolution of Dormancy and Germination. Academic Press, San Diego

Bekker RM, Bakker JP, Grandin U, Kalamees R, Milberg P, Poschlod P, Thompson K, Willems JH (1998) Seed size, shape and vertical distribution in the soil: indicators of seed longevity. Funct Ecol 12:834-842

Bernareggi G, Carbognani M, Petraglia A, Mondoni A (2015) Climate warming could increase seed longevity of alpine snowbed plants. Alpine Bot 125:69-78

Bulgarian Academy of Sciences (2011) Red Data Book of the Republic of Bulgaria: Vol. 1, Plants and Fungi. Ministry of Environment and Waters of Bulgaria (MEWB), Sofia

Carta A, Hanson S, Müller JV (2016) Plant regeneration from seeds responds to phylogenetic relatedness and local adaptation in Mediterranean Romulea (Iridaceae) species. Ecol Evol 6:4166-4178

Castroviejo S, Lainz M, Lopez Gonzalez G, Montserra P, Munoz Garmendia F, Paiva J, Villar L (1990) Flora Iberica Vol. 2: Platanaceae - Plumbaginaceae. Real Jardín Botánico, C.S.I.C, Madrid

Davies H, Probert R (2004) Protocol for comparative seed longevity testing sheet. http:॥www.kew.org/msbp/scitech/publications/comparativelongevity.pdf. Royal Botanic Gardens, Kew, London 
Developmental heat sum influences recalcitrant seed traits in Aesculus hippocastanum across

Donà M, Balestrazzi A, Mondoni A, Rossi G, Ventura L, Buttafava A, Macovei A, Sabatini ME, Valassi A, Carbonera D (2013) DNA profiling, telomere analysis and antioxidant properties as tools for monitoring ex situ seed longevity. Ann Bot 111:987-998 Ellis RH, Roberts EH (1980) Improved equations for the prediction of seed longevity. Ann Bot 45:13-30

Ellis RH, Hong TD, Roberts EH (1985) Handbooks for genebanks 2: handbook of seed technology for genebanks. Vol 1. Principles and methodology. International Board for Plant Genetic Resources, Rome

Ellis RH, Hong TD, Roberts EH (1987) The development of desiccation-tolerance and maximum seed quality during seed maturation in six grain legumes. Ann Bot 59:23-29 FAO/IPGRI (1994) Genebank standards. Food and Agriculture Organisation of the United Nations/International Plant Genetic Resource Institute, Rome Fernández-Pascual E, Jiménez-Alfaro B, Hájek M, Díaz TE, Pritchard HW (2015) Soil thermal buffer and regeneration niche may favour calcareous fen resilience to climate change. Folia Geobot 50:293-301

Flora of North America Editorial Committee (1993) Flora of North America: Volume 5: Magnoliophyta: Caryophyllidae (Part 2). Oxford University Press on Demand Godefroid S, Phartyal SS, Koedam N (2011) Natural versus artificial cold-stratification: which one allows better estimates of soil seed banks in a forest ecosystem?. Curr Sci 101:215-218 Hay FR, Smith RD (2003) Seed maturity: when to collect seeds from wild plants. In: Smith RD, Dickie JB, Linnington SH, Pritchard HW, Probert RJ (ed) Seed conservation: turning science into practice. Royal Botanic Gardens, Kew, London, pp 97-133 Hay FR, Adams J, Manger K, Probert R (2008) The use of non-saturated lithium chloride solutions for experimental control of seed water content. Seed Sci Technol 36:737-746 Hijmans RJ, Cameron SE, Parra JL, Jones PG, Jarvis A (2005) Very high resolution interpolated climate surfaces for global land areas. International J Climatol 25:1965-1978 environment modulates seed longevity. Aust Ecol 35:837-848

472 Koutsovoulou K, Daws MI, Thanos CA (2014) Campanulaceae: a family with small seeds that require light for germination. Ann Bot 113:135-143 

Seed persistence in the field may be predicted by laboratory-controlled aging. Weed Sci 56:523-528 (2014) Environmentally induced transgenerational changes in seed longevity: maternal and genetic influence. Ann Bot 113:1257-1263

Mondoni A, Probert RJ, Rossi G, Vegini E, Hay FR (2011) Seeds of alpine plants are short lived: implications for long-term conservation. Ann Bot 107:171-179

Probert RJ, Daws MI, Hay FR (2009) Ecological correlates of ex situ seed longevity: a comparative study on 195 species. Ann Bot 104:57-69

Probert R, Adams J, Coneybeer J, Crawford A, Hay F (2007) Seed quality for conservation is critically affected by pre-storage factors. Aust J Bot 55:326-335

Rajjou L, Debeaujon I (2008) Seed longevity: survival and maintenance of high germination ability of dry seeds. C R Biol 331:796-805

Saatkamp A, Affre L, Dutoit T, Poschlod P (2011) Germination traits explain soil seed persistence across species: the case of Mediterranean annual plants in cereal fields. Ann Bot 107:415-426

Schwienbacher E, Marcante S, Erschbamer B (2010) Alpine species seed longevity in the soil in relation to seed size and shape - A 5-year burial experiment in the Central Alps. Flora 205:19-25

Sinniah UR, Ellis RH, John P (1998) Irrigation and seed quality development in rapid-cycling Brassica: seed germination and longevity. Ann Bot 82:309-314

Thompson KBSR, Band SR, Hodgson JG (1993) Seed size and shape predict persistence in soil. Funct Ecol 7:236-241

Tutin TG (1980) Flora Europaea. Vol. 1. Lycopodiaceae to Platanaceae. Cambridge University Press, Cambridge

500 Ventura L, Donà M, Macovei A, Carbonera D, Buttafava A, Mondoni A, Rossi G, Balestrazzi 501 A (2012) Understanding the molecular pathways associated with seed vigor. Plant Physiol Bioch 60:196-206

Walck JL, Baskin JM, Baskin CC, Hidayati SN (2005) Defining transient and persistent seed banks in species with pronounced seasonal dormancy and germination patterns. Seed Sci Res 15:189-196

Walters C, Wheeler LM, Grotenhuis JM (2005) Longevity of seeds stored in a genebank: species characteristics. Seed Sci Res 15:1-20 
508 Wang T, Hamann A, Yanchuk A, O’Neill GA, Aitken SN (2006) Use of response functions in 509 selecting lodgepole pine populations for future climates. Glob Change Biol 12:2402-2416

510 Waterworth WM, Masnavi G, Bhardwaj RM, Jiang Q, Bray CM, West CE (2010) A plant DNA 511 ligase is an important determinant of seed longevity. Plant J 63:848-860

512 Welbaum GE, Bradford KJ (1989) Water relations of seed development and germination in 513 muskmelon (Cucumis melo L.) II. Development of germinability, vigour, and desiccation 514 tolerance. J Exp Bot 40:1355-1362 


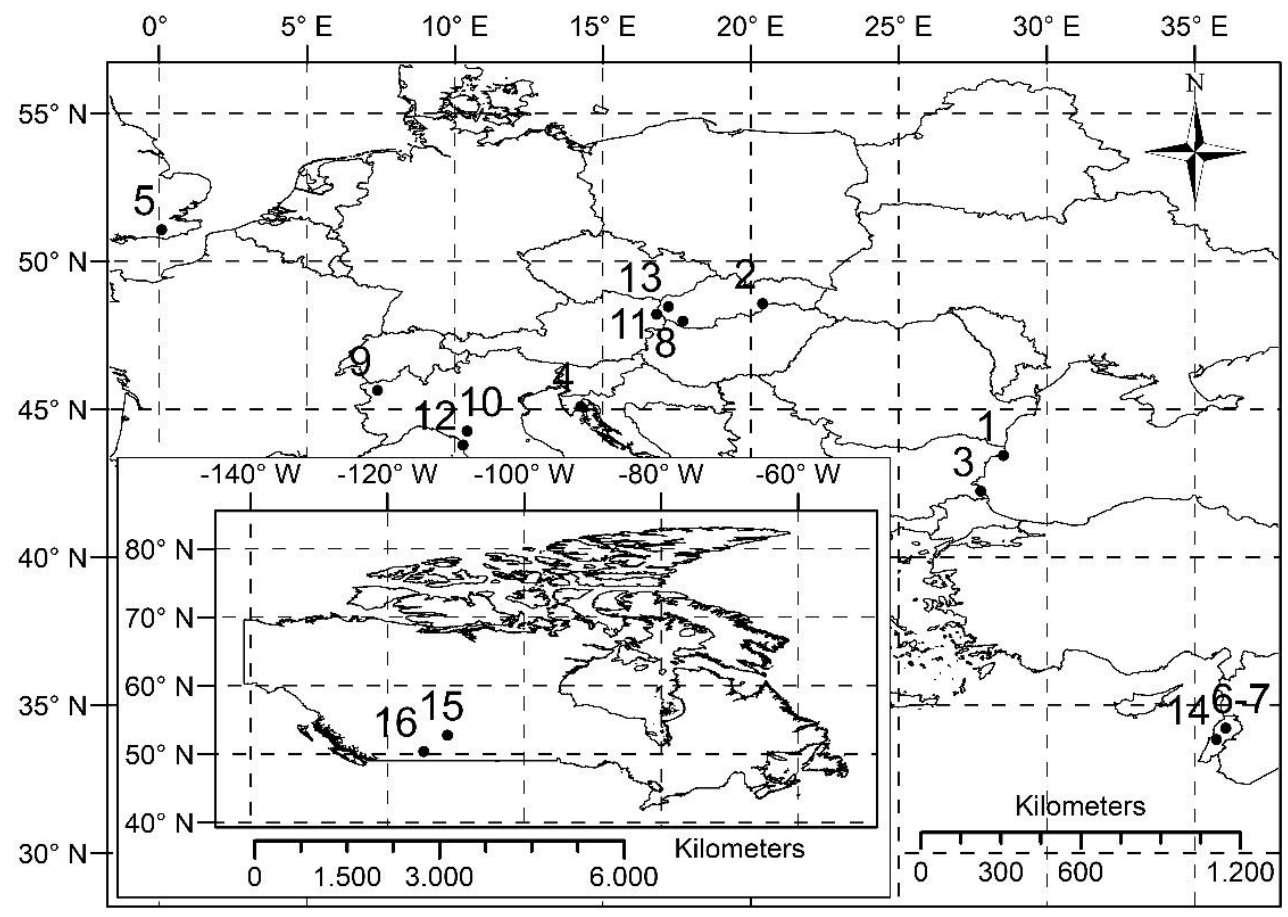

Fig. 1. Map of the collecting sites for the studied accessions. Black circles are followed by identification numbers (for ID no. abbreviations see Table 1).

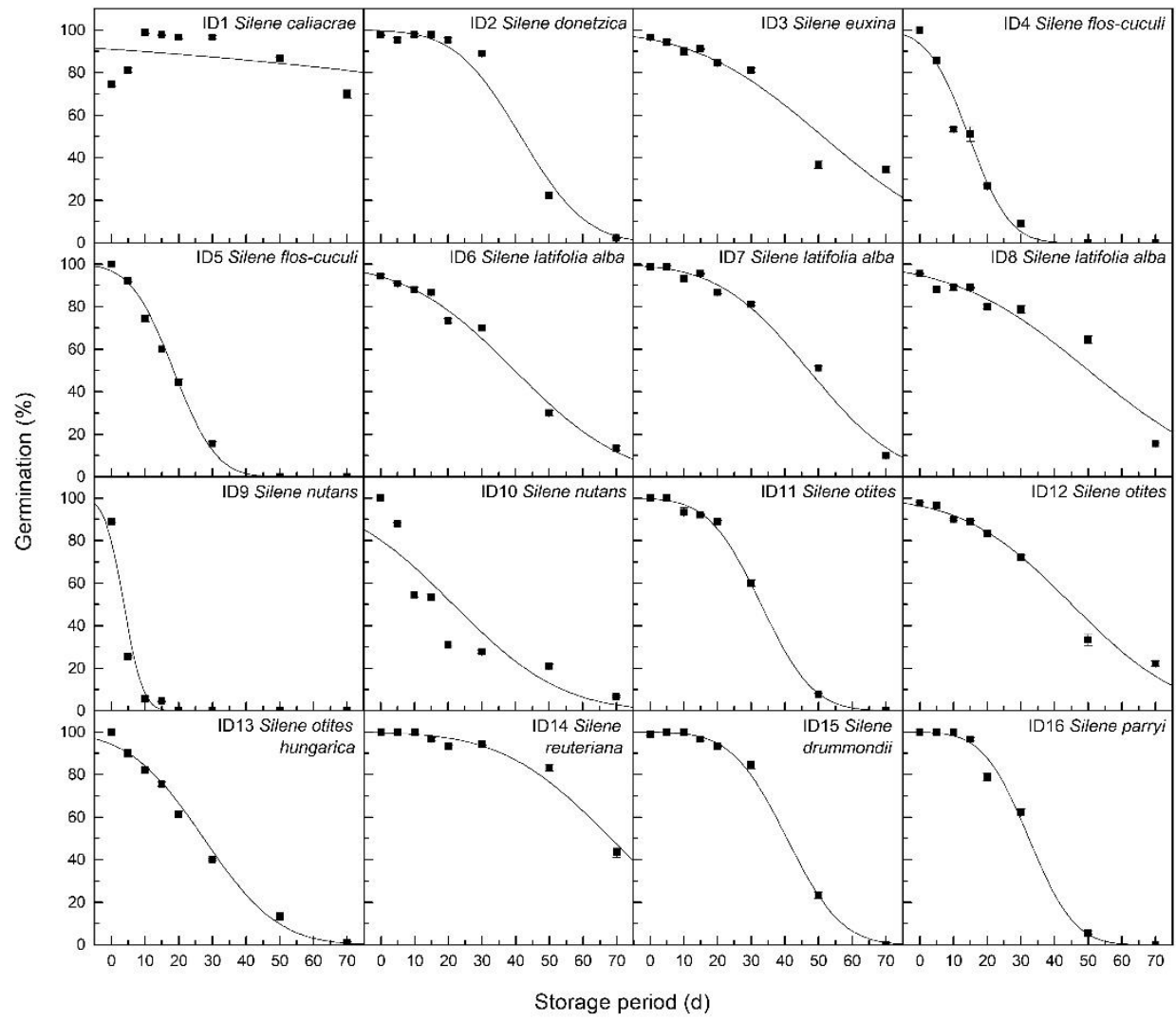

Fig. 2. Survival curves fitted by probit analysis for all Silene accessions aged at $45^{\circ} \mathrm{C}, 60 \%$ RH. 

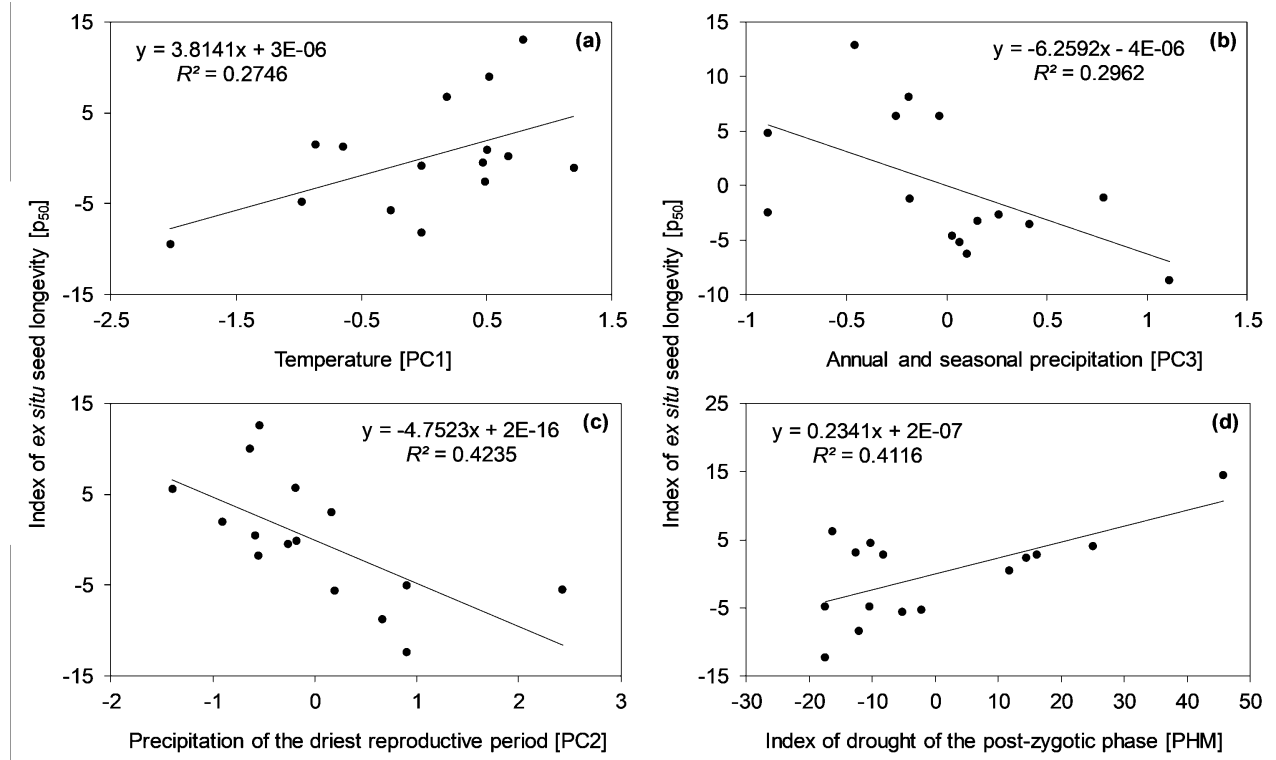

Fig. 3. Relationships between $\mathrm{p}_{50}$ (ex situ seed longevity) and significant predictors derived by multiple regression analysis, (a) PC1 (temperature), (b) PC3 (annual and seasonal mean of precipitation), (c) PC2 (precipitation during the driest months of the reproductive period) and (d) PHM (heat-moisture index of the post-zygotic phase) at population site. Solid lines show the results of partial regression analysis. 
Table 1. Details of accessions used in the study

Classification to species level, provenance (bioregion), time to $50 \%$ viability loss at $45^{\circ} \mathrm{C}, 60 \% \mathrm{RH}$ ( $\mathrm{p}_{50} \pm$ s.e.) and germination conditions used

\begin{tabular}{|c|c|c|c|c|c|}
\hline $\begin{array}{l}\text { ID } \\
\text { no. }\end{array}$ & Species $^{\mathrm{a}}$ & Bioregion $^{b}$ & p50 \pm s.e. (d) & $\begin{array}{l}\text { Seed mass } \pm \\
\text { s.d. }(\mathrm{mg})\end{array}$ & $\begin{array}{c}\text { Germination } \\
\text { temperature }\left({ }^{\circ} \mathrm{C}\right)^{\mathrm{c}}\end{array}$ \\
\hline 1 & Silene caliacrae Jordanov \& Panov & Black Sea & $203.8 \pm 0.09$ & $0.49 \pm 0.004$ & $25 / 15$ \\
\hline 2 & $\begin{array}{l}\text { Silene donetzica subsp. sillingeri } \\
\text { (Hendrych) M. Sourkova }\end{array}$ & Pannonian & $41.6 \pm 0.16$ & $0.44 \pm 0.025$ & 20 \\
\hline 3 & Silene euxina (Rupr.) Hand.-Mazz. & Black Sea & $51.3 \pm 0.10$ & $0.50 \pm 0.002$ & $25 / 15$ \\
\hline 4 & Silene flos-cuculi (L.) Clairv. & Continental & $14.6 \pm 0.12$ & $0.13 \pm 0.002$ & $25 / 15$ \\
\hline 5 & & Atlantic & $18.5 \pm 0.13$ & $0.13 \pm 0.004$ & $25 / 15$ \\
\hline 6 & $\begin{array}{l}\text { Silene latifolia subsp. alba (Miller) } \\
\text { Greuter \& Burdet }\end{array}$ & Anatolian & $39.8 \pm 0.09$ & $1.31 \pm 0.014$ & 20 \\
\hline 7 & & Anatolian & $47.1 \pm 0.13$ & $1.48 \pm 0.026$ & 20 \\
\hline 8 & & Pannonian & $50.1 \pm 0.10$ & $0.64 \pm 0.016$ & 20 \\
\hline 9 & Silene nutans $\mathrm{L}$. & Alpine & $3.7 \pm 0.13$ & $0.34 \pm 0.010$ & $25 / 15$ \\
\hline 10 & & Continental & $21.5 \pm 0.08$ & $0.47 \pm 0.011$ & $25 / 15$ \\
\hline 11 & Silene otites subsp. otites (L.) Wibel & Continental & $32.9 \pm 0.16$ & $0.21 \pm 0.003$ & $25 / 15$ \\
\hline 12 & & Mediterranean & $45.1 \pm 0.10$ & $0.37 \pm 0.005$ & $25 / 15$ \\
\hline 13 & Silene otites subsp. hungarica Wringley & Pannonian & $27.4 \pm 0.10$ & $0.16 \pm 0.006$ & $25 / 15$ \\
\hline 14 & Silene reuteriana Boiss. \& Blanche & Anatolian & $68.3 \pm 0.18$ & $0.30 \pm 0.010$ & 15 \\
\hline 15 & Silene drummondii Hook. & Boreal & $40.6 \pm 0.20$ & $0.13 \pm 0.002$ & $25 / 15$ \\
\hline 16 & $\begin{array}{l}\text { Silene parryi (S. Watson) C.L. Hitchcock } \\
\text { \& Maguire }\end{array}$ & Boreal & $32.4 \pm 0.20$ & $0.22 \pm 0.002$ & $25 / 15$ \\
\hline
\end{tabular}

aplant names follow the International Plant Name Index (IPNI: http://www.ipni.org/)

${ }^{b}$ Biogeographical regions follow EEA reports on bioregions (http://www.eea.europa.eu/)

${ }^{c}$ Optimal conditions for germination estimated for each accession (Zani and Müller, unpublished data) 
Table 2. Traits and index of seed bank formation

Index of delayed germination $\left(\mathrm{T}_{50}\right)$ and relative germination rates for cold stratification pre-treatment $\left(\Delta G_{\mathrm{CS}}\right)$, light requirement (PGI) and fluctuating temperatures $\left(\Delta G_{\mathrm{FT}}\right)$ of the studied accessions. The index of soil seed bank formation (SBI) is calculated by PCA using SB traits $\left(\Delta G_{\mathrm{CS}}, T_{50}\right.$, PGI, and $\Delta G_{\mathrm{FT}}$; Table 4$)$. The type of soil seed bank is estimated considering both, SBI and the germination and dispersal events

\begin{tabular}{|c|c|c|c|c|c|c|c|c|}
\hline ID no. & Dispersal Peak ${ }^{\mathrm{a}}$ & Germination $^{\mathrm{b}}$ & $\Delta G_{\mathrm{CS}}$ & $\mathrm{T}_{50}$ & PGI & $\Delta G_{\mathrm{FT}}$ & SBI & Type of soil seed bank \\
\hline 1 & November & May & 15.38 & 3.55 & 1.00 & 28.85 & 1.89 & Flood-winter bank ${ }^{c, d}$ \\
\hline 2 & June-July & June-July & -1.16 & 1.31 & 0.01 & 0.00 & -1.10 & $\mathrm{No}^{\mathrm{e}}$ \\
\hline 3 & October & June & 9.54 & 2.08 & 0.00 & 1.82 & 0.20 & Winter bank ${ }^{\mathrm{c}}$ \\
\hline 4 & May & August & -5.88 & 3.93 & 0.49 & 15.38 & 1.10 & Flood bank ${ }^{\mathrm{d}}$ \\
\hline 5 & May & August & -2.86 & 5.72 & 0.29 & 30.43 & 1.89 & Flood bank ${ }^{\mathrm{d}}$ \\
\hline 6 & September & September & -12.05 & 3.44 & 0.19 & 0.00 & -0.83 & $\mathrm{No}^{\mathrm{e}}$ \\
\hline 7 & September & September & -11.48 & 3.01 & 0.16 & 0.00 & -0.94 & $\mathrm{No}^{\mathrm{e}}$ \\
\hline 8 & May & May & 1.54 & 3.47 & 0.11 & -1.75 & -0.49 & $\mathrm{No}^{\mathrm{e}}$ \\
\hline 9 & November & July & 11.80 & 3.86 & 0.30 & 1.31 & 0.51 & Winter bank ${ }^{\mathrm{c}}$ \\
\hline 10 & October & July & 3.86 & 3.25 & 0.16 & 1.69 & 0.31 & Winter bank ${ }^{\mathrm{c}}$ \\
\hline 11 & May-June & May-June & 0.00 & 1.58 & 0.00 & 0.00 & -1.00 & $\mathrm{No}^{\mathrm{e}}$ \\
\hline 12 & September & September & -1.41 & 2.62 & 0.08 & 0.00 & -0.53 & $\mathrm{No}^{\mathrm{e}}$ \\
\hline 13 & May-June & May-June & -1.41 & 1.89 & 0.00 & 0.00 & -0.98 & $\mathrm{No}^{\mathrm{e}}$ \\
\hline 14 & September & October & 0.59 & 4.19 & 0.85 & -1.69 & 0.25 & Delayed germination $^{\mathrm{f}}$ \\
\hline 15 & November & June & 11.11 & 3.63 & 0.68 & 14.38 & 0.75 & Winter bank ${ }^{\mathrm{c}}$ \\
\hline 16 & November & June & 9.09 & 3.76 & 0.60 & 13.09 & 0.62 & Winter bank ${ }^{\mathrm{c}}$ \\
\hline
\end{tabular}

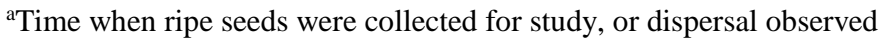

${ }^{b}$ Main period of germination estimated by Zani and Müller (unpublished data)

'Seeds remain dormant during winter

${ }^{\mathrm{d}}$ Seeds of wetland species remain dormant during the flooding season

eSeeds germinate immediately after dispersal

fSeeds delay germination to spread the risk of emergence failure in mesic environments 
Table 3. Climatic variables and drought index

Temperatures and precipitation are the 50 years averages $(1950-2000)$ at annual $(\mathrm{A}=$ annual $)$ and seasonal scales $(\mathrm{W}=$ winter; $\mathrm{Sp}=\mathrm{spring} ; \mathrm{Su}=\mathrm{summer} ; \mathrm{Au}$ $=$ autumn), and of the plant life cycle phases (Pre = pre-zygotic; Post $=$ post-zygotic; Dis $=$ post-dispersal). Drought during the seed maturation period is given by PHM = heat-moisture index of the post-zygotic phase

\begin{tabular}{|c|c|c|c|c|c|c|c|c|c|c|c|c|c|c|c|c|c|c|}
\hline \multirow{2}{*}{ ID no. } & \multicolumn{8}{|c|}{ Temperature $\left({ }^{\circ} \mathrm{C}\right)$} & \multicolumn{8}{|c|}{ Precipitation $(\mathrm{mm})$} & \multirow{2}{*}{\multicolumn{2}{|c|}{$\begin{array}{l}\text { Drought }[\mathrm{HM} \text { index }] \\
\text { PHM }\end{array}$}} \\
\hline & $\mathrm{A}$ & $\mathrm{W}$ & $\mathrm{Sp}$ & $\mathrm{Su}$ & $\mathrm{Au}$ & Pre & Post & Dis & A & $\mathrm{W}$ & $\mathrm{Sp}$ & $\mathrm{Su}$ & $\mathrm{Au}$ & Pre & Post & Dis & & \\
\hline 1 & 12.3 & 3.3 & 10.5 & 21.3 & 14.0 & 19.1 & 20.3 & 11.6 & 42.5 & 44.3 & 38.3 & 39.3 & 48.0 & 40.7 & 38.5 & 51.5 & 312.5 & Extreme \\
\hline 2 & 8.4 & -2.1 & 8.8 & 17.9 & 9.0 & 13.9 & 8.8 & 17.8 & 49.8 & 29.7 & 48.0 & 75.7 & 45.7 & 39.8 & 48.0 & 78.5 & 39.1 & $\mathrm{NO}$ \\
\hline 3 & 13.3 & 4.5 & 11.7 & 22.0 & 15.1 & 11.7 & 22.0 & 17.6 & 47.8 & 54.7 & 44.7 & 34.7 & 57.0 & 44.7 & 34.7 & 48.0 & 92.3 & Moderate \\
\hline 4 & 13.9 & 6.3 & 12.4 & 22.0 & 14.8 & 20.0 & 10.4 & 18.4 & 102.1 & 107.0 & 87.7 & 78.0 & 135.7 & 102.0 & 88.5 & 85.0 & 23.0 & NO \\
\hline 5 & 9.5 & 3.7 & 8.4 & 15.8 & 10.3 & 13.5 & 8.4 & 15.6 & 154.8 & 162.0 & 158.7 & 153.0 & 145.7 & 64.3 & 53.3 & 50.5 & 34.4 & NO \\
\hline 6 & 7.2 & -0.7 & 5.0 & 14.8 & 9.9 & 11.0 & 15.8 & 13.8 & 76.9 & 175.0 & 82.3 & 2.7 & 47.7 & 21.5 & 1.0 & 4.0 & 89.1 & Moderate \\
\hline 7 & 7.2 & -0.7 & 5.0 & 14.8 & 9.9 & 11.0 & 15.8 & 13.8 & 76.9 & 175.0 & 82.3 & 2.7 & 47.7 & 21.5 & 1.0 & 4.0 & 89.1 & Moderate \\
\hline 8 & 10.1 & 0.0 & 10.4 & 19.7 & 10.5 & 10.4 & 19.6 & 15.4 & 46.7 & 37.0 & 42.7 & 63.7 & 43.3 & 42.7 & 61.5 & 49.3 & 48.1 & $\mathrm{NO}$ \\
\hline 9 & -1.4 & -7.7 & -3.5 & 5.6 & 0.1 & 5.6 & 2.3 & -5.4 & 60.3 & 65.0 & 53.3 & 51.7 & 71.3 & 153.0 & 143.5 & 161.5 & 8.5 & NO \\
\hline 10 & 5.8 & -1.3 & 3.9 & 13.6 & 7.1 & 9.7 & 14.7 & 9.4 & 71.8 & 63.3 & 67.0 & 62.3 & 94.7 & 68.0 & 61.5 & 92.5 & 40.1 & NO \\
\hline 11 & 9.9 & 0.3 & 10.0 & 19.3 & 10.2 & 15.0 & 7.6 & 16.6 & 53.0 & 38.7 & 50.0 & 76.3 & 47.0 & 49.8 & 43.0 & 71.0 & 40.8 & NO \\
\hline 12 & 14.7 & 7.6 & 13.3 & 22.1 & 15.8 & 13.3 & 21.6 & 21.6 & 75.9 & 86.0 & 72.0 & 40.0 & 105.7 & 72.0 & 35.5 & 63.5 & 89.1 & Moderate \\
\hline 13 & 9.3 & -0.4 & 9.4 & 18.6 & 9.7 & 15.6 & 7.0 & 16.1 & 58.5 & 40.7 & 53.7 & 89.3 & 50.3 & 68.8 & 45.5 & 80.5 & 37.4 & NO \\
\hline 14 & 14.6 & 7.0 & 13.0 & 21.6 & 16.7 & 13.0 & 21.1 & 21.3 & 92.3 & 221.3 & 94.7 & 1.0 & 52.0 & 94.7 & 1.0 & 3.0 & 158.0 & Extreme \\
\hline 15 & 2.1 & -13.4 & 2.8 & 15.9 & 3.2 & 15.9 & 7.5 & -8.9 & 34.9 & 19.0 & 28.7 & 68.7 & 23.3 & 68.7 & 27.5 & 18.0 & 63.5 & Moderate \\
\hline 16 & 0.7 & -9.6 & -0.3 & 11.0 & 2.0 & 11.0 & 5.2 & -6.6 & 51.9 & 47.0 & 54.3 & 64.7 & 41.7 & 64.7 & 43.5 & 42.5 & 34.9 & NO \\
\hline
\end{tabular}




\section{Table 4. Results of Principal Component Analyses (PCA) for seed bank (SB) traits and climatic variables}

Correlations of principal components (PCs) of PCA ordination with (a) SB traits $\left(\Delta G_{\mathrm{CS}}, \mathrm{T}_{50}, \mathrm{PGI}\right.$, and $\left.\Delta G_{\mathrm{FT}}\right)$ and with (b) temperatures (temp) and precipitation (pr) at annual (A $=$ annual) and seasonal scales $(\mathrm{W}=$ winter; $\mathrm{Sp}=$ spring; $\mathrm{Su}=$ summer; $\mathrm{Au}=$ autumn $)$, and of the plant life cycle phases $($ Pre = pre-zygotic; Post = post-zygotic; Dis = post-dispersal). The most explicative component (PC1) of PCA for SB traits was retained as index of seed bank formation (SBI)

\begin{tabular}{|c|c|c|c|c|c|c|c|c|c|c|c|c|c|c|c|c|c|c|c|}
\hline (a) & $\mathrm{PC} 1$ & $\mathrm{PC} 2$ & $\mathrm{PC} 3$ & $\mathrm{PC} 4$ & $\Delta \mathrm{G}_{\mathrm{CS}}$ & $\mathrm{T}_{50}$ & PGI & $\Delta \mathrm{G}_{\mathrm{FT}}$ & & & & & & & & & & & \\
\hline Eigenvalue & 2.813 & 0.673 & 0.293 & 0.221 & & & & & & & & & & & & & & & \\
\hline Variance & 70.32 & 16.83 & 7.32 & 5.54 & & & & & & & & & & & & & & & \\
\hline$\Delta \mathrm{G}_{\mathrm{CS}}$ & $0.810^{* * *}$ & & & & - & & & & & & & & & & & & & & \\
\hline $\mathrm{T}_{50}$ & $0.735 * * *$ & & & & 0.333 & - & & & & & & & & & & & & & \\
\hline PGI & $0.868 * * *$ & & & & 0.603 & 0.616 & - & & & & & & & & & & & & \\
\hline$\Delta \mathrm{G}_{\mathrm{FT}}$ & $0.711 * * *$ & & & & 0.676 & 0.594 & 0.766 & - & & & & & & & & & & & \\
\hline (b) & PC1 & $\mathrm{PC} 2$ & $\mathrm{PC} 3$ & $\mathrm{PC} 4$ & $\mathrm{~A}_{\text {temp }}$ & $\mathrm{W}_{\text {temp }}$ & $\mathrm{Sp}_{\text {temp }}$ & $\mathrm{Su}_{\text {temp }}$ & $\mathrm{Au}_{\text {temp }}$ & Pre $_{\text {temp }}$ & Post $_{\text {temp }}$ & Dis & $\mathrm{A}_{\mathrm{pr}}$ & $\mathrm{W}_{\mathrm{pr}}$ & $\mathrm{Sp}_{\mathrm{pr}}$ & $\mathrm{Su}_{\mathrm{pr}}$ & $\mathrm{Au}_{\mathrm{pr}}$ & $\operatorname{Pre}_{\mathrm{pr}}$ & Post $_{\mathrm{pr}}$ \\
\hline Eigenvalue & 7.216 & 3.618 & 2.423 & 1.391 & & & & & & & & & & & & & & & \\
\hline Variance & 45.10 & 22.61 & 15.14 & 8.69 & & & & & & & & & & & & & & & \\
\hline $\mathrm{A}_{\text {temp }}$ & $0.965 * * *$ & -0.156 & 0.189 & & - & & & & & & & & & & & & & & \\
\hline $\mathrm{W}_{\text {temp }}$ & $0.849^{* * *}$ & -0.050 & 0.437 & & 0.929 & - & & & & & & & & & & & & & \\
\hline $\mathrm{Sp}_{\mathrm{temp}}$ & $0.976 * * *$ & -0.118 & 0.079 & & 0.978 & 0.851 & - & & & & & & & & & & & & \\
\hline $\mathrm{Su}_{\text {temp }}$ & $0.955 * * *$ & -0.199 & -0.096 & & 0.931 & 0.732 & 0.967 & - & & & & & & & & & & & \\
\hline $\mathrm{Au}_{\text {temp }}$ & $0.923^{* * *}$ & -0.261 & 0.235 & & 0.988 & 0.934 & 0.942 & 0.900 & - & & & & & & & & & & \\
\hline $\mathrm{Pre}_{\text {temp }}$ & $0.649 * *$ & 0.085 & -0.151 & & 0.540 & 0.329 & 0.597 & 0.688 & 0.494 & - & & & & & & & & & \\
\hline Post $_{\text {temp }}$ & $0.611 * *$ & -0.567 & 0.051 & & 0.711 & 0.660 & 0.636 & 0.653 & 0.770 & 0.083 & - & & & & & & & & \\
\hline Dis $_{\text {temp }}$ & $0.839 * * *$ & -0.157 & 0.319 & & 0.900 & 0.910 & 0.876 & 0.753 & 0.889 & 0.309 & 0.590 & - & & & & & & & \\
\hline$A_{p r}$ & 0.139 & 0.182 & $0.958 * * *$ & & 0.274 & 0.483 & 0.197 & 0.025 & 0.284 & 0.053 & -0.024 & 0.366 & - & & & & & & \\
\hline $\mathrm{W}_{\mathrm{pr}}$ & 0.038 & -0.437 & $0.848 * * *$ & & 0.281 & 0.451 & 0.155 & 0.039 & 0.379 & -0.119 & 0.304 & 0.374 & 0.715 & - & & & & & \\
\hline $\mathrm{Sp}_{\mathrm{pr}}$ & 0.084 & 0.057 & $0.975 * * *$ & & 0.243 & 0.454 & 0.163 & -0.010 & 0.267 & -0.012 & 0.005 & 0.360 & 0.987 & 0.769 & - & & & & \\
\hline $\mathrm{Su}_{\mathrm{pr}}$ & 0.026 & $0.719^{* * * *}$ & 0.121 & & -0.109 & -0.106 & -0.005 & -0.071 & -0.229 & 0.240 & -0.562 & -0.085 & 0.353 & -0.357 & 0.290 & - & & & \\
\hline $\mathrm{Au}_{\mathrm{pr}}$ & 0.291 & 0.360 & $0.696^{* * *}$ & & 0.312 & 0.417 & 0.238 & 0.096 & 0.283 & 0.140 & -0.025 & 0.327 & 0.811 & 0.307 & 0.726 & 0.481 & - & & \\
\hline $\operatorname{Pre}_{\mathrm{pr}}$ & -0.233 & $0.673 * * *$ & 0.158 & & -0.250 & -0.104 & -0.279 & -0.342 & -0.277 & -0.181 & -0.410 & -0.326 & 0.178 & -0.015 & 0.081 & 0.177 & 0.357 & - & \\
\hline Post $_{\mathrm{pr}}$ & -0.231 & $0.894 * * *$ & -0.076 & & -0.355 & -0.197 & -0.354 & -0.426 & -0.423 & -0.222 & -0.514 & -0.328 & 0.011 & -0.413 & -0.098 & 0.565 & 0.381 & 0.731 & - \\
\hline $\operatorname{Dis}_{\mathrm{pr}}$ & -0.133 & $0.879 * * *$ & -0.155 & & -0.273 & -0.111 & -0.271 & -0.361 & -0.347 & -0.211 & -0.481 & -0.183 & -0.072 & -0.482 & -0.172 & 0.504 & 0.337 & 0.653 & 0.924 \\
\hline
\end{tabular}

Levels of significance for the PCA results: *, $P<0.05 ; * *, P<0.01 ; * * *, P<0.001$

Significant values $(P<0.05)$ are given in bold in the correlation matrixes 
Table 5. Results of the multiple regression analysis and correlation matrix of explanatory variables

Relationship between seed longevity ( $\mathrm{p}_{50}$ ), seed mass ( $\mathrm{mg}$ ), index of drought during the post-zygotic phase (PHM), index of seed bank formation (SBI), and climatic traits expressed as $\mathrm{PC}$-axes scores, i.e. temperature (PC1), precipitation during the driest months of the reproductive period (PC2), and annual and seasonal precipitation (PC3)

\begin{tabular}{lcccccccc}
\hline Term & Coefficient & $t$-value & Seed mass & PHM & SBI & PC1 & PC2 & PC3 \\
\hline Full model & & & & & & & & \\
Constant & 28.818 & $3.172^{*}$ & & & & & \\
Seed mass & -6.976 & -0.805 & - & & & & \\
PHM & 0.181 & 1.659 & 0.358 & - & & & \\
SBI & -0.084 & -0.026 & -0.407 & -0.208 & - & & \\
PC1 & 3.904 & 1.707 & -0.180 & 0.310 & -0.163 & - & & \\
PC2 & -9.711 & -1.990 & -0.499 & -0.424 & 0.426 & 0.018 & - & \\
PC3 & -3.936 & -1.479 & 0.153 & 0.205 & 0.453 & 0.083 & -0.019 & - \\
Reduced model & & & & & & & & \\
Constant & 22.514 & $4.061^{* * *}$ & & & & & & \\
PHM & 0.234 & $2.645^{* * *}$ & & & & & \\
PC1 & 3.814 & $1.946^{*}$ & & & & & \\
PC2 & -4.752 & $-2.710^{* * *}$ & & & & & \\
PC3 & -6.259 & $-2.052^{* *}$ & & & & & \\
\hline
\end{tabular}

$*, P<0.05 ; * *, P<0.01 ; * * *, P<0.001$

Click here to download Tables.docx:

http://www.editorialmanager.com/ecol/download.aspx?id=111232\&guid=587ee626-d7fc4e7e-b197-9313ec315060\&scheme $=1$

Click here to access/download Electronic Supplementary Material Table S1.pdf:

http://www.editorialmanager.com/ecol/download.aspx?id=111239\&guid=bdcbc66a-5db8$\underline{4722-a 8 b 6-6 e c c 3 f b e 20 a a \& s c h e m e=1}$ 